\title{
Sympathetic Neurons Expressing Cholinergic Properties Are Poised to Allocate Choline Symmetrically between Acetylcholine and the Phosphatidylcholine-Generating Pathway in Growing Neurites
}

\author{
Hana S. Suidan ${ }^{1, a}$ and Aviva M. Tolkovsky ${ }^{2}$ \\ 'Department of Biochemistry, University of Cambridge, Cambridge CB2 1QW and ${ }^{2}$ Department of Human Anatomy, \\ University of Oxford, Oxford OX13QX, United Kingdom
}

We have examined the question of how regenerating sympathetic neurons that are concomitantly induced to become cholinergic regulate choline allocation between $\mathrm{ACh}$ and the phospholipid synthetic pathway. The allocation of choline into ACh increased parabolically with time in culture, and by 3 weeks, cultures with neurites of $\sim 6 \mathrm{~mm}$ length were incorporating over $85 \%$ of the choline locally in the neurites into four major metabolites: ACh, phosphorylcholine, cytidine diphosphocholine, and phosphatidylcholine. The nearequivalent distribution of labeled choline between intracellular choline, $\mathrm{ACh}$, and phosphorylcholine was independent of time (5 min to $6 \mathrm{hr}$ ) and choline concentration (0.125-30 $\mu \mathrm{M})$, phosphatidylcholine being the sole metabolite whose level in the neurites increased steadily with incubation time. Relative choline distribution into $\mathrm{ACh}$ and phosphorylcholine was unaltered even after a brief depolarizing prepulse, which caused a two- to fourfold enhancement in the total choline incorporated. These observations, allied with the similar halfsaturation constants and $V_{\max }$ values of CAT and choline kinase for intracellular choline, suggest that growing sympathetic neurons are poised to allocate choline symmetrically between the synthesis of $\mathrm{ACh}$ and phosphatidylcholine in the neurites. When, however, the supply of choline was limited either by replacement of $\mathrm{Na}^{+}$in the medium with $\mathrm{N}$ methyl-D-glucamine, or by vesamicol, a $90-97 \%$ reduction in intracellular choline caused a similar decline in ACh levels but synthesis of metabolites of the phosphatidylcholine pathway was maintained unperturbed, as if no drug was present. We suggest that this can be accounted for by a 10fold increase in choline kinase activity. Thus, growing sympathetic neurons that express cholinergic properties not only maintain their chief cellular phosphatidylcholine-synthesizing activity concomitantly with ACh synthesis in the neurites, but may also preserve phosphatidylcholine synthesis more effectively than ACh synthesis when the supply of choline is perturbed. Relinquishing ACh synthesis during growth may be one way of conserving and encouraging neurite regeneration.

\footnotetext{
Received Apr. 23, 1992; revised Sept. 8, 1992; accepted Sept. 24, 1992.

We are grateful to Dr. Kate Nobes for critical reading of the manuscript and to the MRC, the Wellcome Trust (A.M.T.), and Trinity College, Cambridge (H.S.S.), for support.

Correspondence should be addressed to Dr. A. M. Tolkovsky, Department of Human Anatomy, University of Oxford, South Parks Road, Oxford OX13QX, United Kingdom.

aPresent address: Friedrich Miescher-Institut, P.O. Box 2543, Basel CH-4002, Swilzerland.

Copyright (C) 1993 Society for Neuroscience $0270-6474 / 93 / 131190-12 \$ 05.00 / 0$
}

IKey words: choline uptake, ChAT, phospholipid synthesis, neurite outgrowth, hemicholinium 3, vesamicol, cultured rat sympathetic neurons]

In growing cholinergic neurons, two metabolic pathways compete for choline. One, catalyzed by choline kinase (CK), gives rise to phosphatidylcholine (PtdCh), a major component of cellular membranes; the other, catalyzed by CAT, produces $\mathrm{ACh}$ (Yavin, 1976). Several studies suggest that provision of choline can be rate limiting for both pathways, as enrichment of dietary choline can alter the amount of choline that is incorporated into these two products (Millington and Wurtman, 1982; Wecker and Schmidt, 1989), and it is also well established that choline uptake is rapidly increased when synaptosomal preparations or neurons are stimulated by depolarization (Simon and Kuhar, 1975; see Ducis, 1988, for review). It is therefore important to determine how growing neurons regulate the allocation of choline between these two pathways, especially since neurons receive preganglionic innervation during the time they grow toward their targets, and thus may be subjected to depolarizing stimuli (Rubin, 1985). In addition to its utilization from extracellular sources, choline can also be obtained from PtdCh by hydrolysis with phospholipase D (Hatori and Kanfer, 1985) or phospholipase $\mathrm{C}$, and it has been suggested that choline supply from lipids is sufficient to sustain normal $\mathrm{ACh}$ synthesis in mouse brain synaptosomes (Yavin et al., 1989), but whether this choline is sufficient to maintain a steady state between $\mathrm{ACh}$, free choline, and PtdCh in growing neurons is not clear.

Several factors appear to regulate neuronal choline metabolism. Ando et al. (1987) showed that depolarization of the rat superior cervical ganglion (SCG) or its exposure to various concentrations of choline differentially altered the activity of CAT and $\mathrm{CK}$ when assayed in vitro. However, in this case the enzymes were not competing for a common pool of choline because both enzymes were derived from different cells. In neuronal cell lines, choline uptake was enhanced when cells were deprived of sodium, when treated with sodium azide and iodoacetatc (Mclaga and Howard, 1981) or with diacylglycerol or phorbol esters (Liscovitch et al., 1987); in other experiments choline uptake was inhibited by arachidonic acid metabolites (Boksa et al., 1988). The consequences of these regulatory events for the partitioning of choline between its various metabolites were not determined.

Regenerating neurons pose special constraints on choline utilization, as the demand for phospholipid synthesis will be enhanced severalfold compared to neurons that have established functional contacts with their targets and have effectively stopped 
growing. Rat SCG neurons are particularly useful for studying choline allocation between ACh and phospholipid because they are induced to acquire a cholinergic phenotype when grown in serum-containing media (Iacovitti et al., 1982; Wolinsky and Patterson, 1985). Little is known about how choline utilization is controlled in such cells. The major site of PtdCh synthesis is the endoplasmic reticulum (ER) (Kennedy, 1962; Pelech and Vance, 1984; Bishop and Bell, 1988) and would thus be predicted to be situated in the cell body. However, axons contain abundant "axoplasmic reticulum," a network of membranes that appear to extend from the cell body ER, suggesting that lipid biosynthesis may also proceed in the neurites, at the same location as ACh synthesis (Fonnum et al., 1973). Indeed, the synthesis of phospholipids in extruded axoplasm has been previously reported (Tanaka et al., 1987). If this is the case, then the suggestion that the delivery of membranes from the cell body by fast axonal transport may be the only mechanism for determining the rate of neurite outgrowth (Longo and Hammerschlagg, 1980) may have to be modified.

This work was thus aimed at resolving two questions. (1) How active is phospholipid biosynthesis in growing neurites? (2) How is the allocation of choline between PtdCh and ACh controlled? For this study, we used 2-3-week-old SCG explants with a mixed adrenergic/cholinergic phenotype (Chun and Patterson, 1977; Ross et al., 1977; Johnson et al., 1980b), as we have shown previously that "biochemically intact" neurites can be easily separated from cell bodies, enabling the independent study of metabolic processes in neurites (Tolkovsky and Suidan, 1987).

A preliminary account of this work has been described (Suidan, 1989).

\section{Materials and Methods}

Materials. Acctylthiocholinc, 1,5-bis-(4-allyldimethylammoniumdiphenyl)-pentane-3-one dibromide (BW284C51), eserine hemisulfate, hemicholinium 3 (HC-3), $N$-methyl-D-glucamine (NMG), and tetraisopropyl pyrophosphoramide (iso-OMPA), and $\mathrm{ACh}$, choline, phosphorylcholine (PCh), and cytidine diphosphocholine (CDP-Ch) used as chromatography markers, were from Sigma (Poole, UK). Lipids were a gift from Dr. Gerry Smith, University of Cambridge, and vesamicol (AH5183) was a gift from Dr. Pedro Lowenstein, University of Oxford. Methyl- ${ }^{3} \mathrm{H}$-choline $(74-80 \mathrm{Ci} / \mathrm{mmol}, 12.5-13.5 \mu \mathrm{M})$ and methyl- ${ }^{14} \mathrm{C}$ choline $(56 \mathrm{mCi} / \mathrm{mmol}, 3.57 \mathrm{~mm})$ were obtained from Amersham International plc. All other chemicals were of the highest grade commercially available.

Cell culture. Explants and single cells were prepared from SCG of 1-d-old rats and were cultured on collagen-coated coverslips (13 mm) or dishes as described previously (Suidan et al., 1991). Enriched L15$\mathrm{CO}_{2}$ growth medium was prepared essentially as described by Hawrot and Patterson (1979) but contained $4.4 \%$ rat serum and $80-100 \mathrm{ng} / \mathrm{ml}$ 2.5S NGF, prepared according to Mobley et al. (1976). It is estimated that the growth medium contained $\sim 70 \mu \mathrm{M}$ choline. After 3 weeks in culture, less than $5 \%$ of the cells were non-neuronal.

Choline uptake. Cultures were washed free of choline by two $5 \mathrm{~min}$ incubations at $37^{\circ} \mathrm{C}$ in wells containing $3 \mathrm{ml}$ of a saline containing $\mathrm{L} 15$ salts (L15-saline) at pH 7.4 composed of (in $\mathrm{mM}$ ) NaCl, 137; KCl, 5.4; $\mathrm{CaCl}_{2}, 1-3 ; \mathrm{MgCl}_{2}, 1 ; \mathrm{MgSO}_{4}, 0.8 ; \mathrm{Na}_{2} \mathrm{HPO}_{4}, 1.34 ; \mathrm{KH}_{2} \mathrm{PO}_{4}, 0.44 ;$ L-glutamine, 1.9; HEPES, 10; with phenol red, $10 \mu \mathrm{g} / \mathrm{ml}$; and glucose, $0.57 \%$. Coverslips were transferred onto brass rings and $100-125 \mu 1$ of L15-saline containing labeled choline was added. After the indicated times at $37^{\circ} \mathrm{C}$, coverslips were washed three times for $3 \mathrm{~min}$ each in wells containing $3 \mathrm{ml}$ of $\mathrm{L} 15$-saline at $37^{\circ} \mathrm{C}$ and transferred into scintillation vials containing $0.5 \mathrm{ml}$ of $1 N \mathrm{HCl}$ and $4 \mathrm{ml}$ of scintillant (OptiPhase Safe or HiSafe, LKB).

Analysis of labeled choline metabolites. Choline metabolites were extracted by vigorous vortexing of the washed coverslip in a glass tube containing an ice-cold mix of $0.5 \mathrm{ml}$ of chloroform and $0.5 \mathrm{ml}$ of an aqueous solution consisting of $60 \%$ methanol, $1.7 \mathrm{mg} / \mathrm{ml}$ choline, 2.5 $\mathrm{mg} / \mathrm{ml} \mathrm{ACh}$, and $15 \mu \mathrm{g} / \mathrm{ml}$ eserine. The tubes were spun briefly and their contents were transferred to microfuge tubes that were spun at high speed at $4^{\circ} \mathrm{C}$ for $1 \mathrm{~min}$ to separate the layers. The lower, chloroformic phase contained the lipids and about $2 \%$ of the labeled $\mathrm{ACh}$, but no choline, $\mathrm{PCh}$, or CDP-Ch were detected. The aqueous phase contained no significant labeled PtdCh, measured using $\mathrm{L}-\alpha-\mathrm{PtdCh}, \beta-$ ${ }^{14} \mathrm{C}$-arachidonyl- $\gamma$-steroyl. To separate the water-soluble metabolites, $5-20 \mu 1$ of the aqueous extract was applied in $2.5 \mu 1$ lots onto a cellulose thin-layer chromatography (TLC) plate (Macherey-Nagel) divided into $1.5 \mathrm{~cm}$ lanes. Spots $(2.5 \mu \mathrm{l})$ of CDP-Ch $(10 \mathrm{~mm}), \mathrm{PCh}(70 \mathrm{mg} / \mathrm{ml})$, and betaine $(10 \mathrm{~mm})$ were applied before the sample. To obtain good scparations, it was essential that $\mathrm{CDP}-\mathrm{Ch}$ was applied before and separately from PCh. Plates were developed in $n$-butanol:ethanol:acetic acid:water (7:2:1:3) essentially according to Marchbanks and Israel (1971) and dried, and CDP-Ch was identified under short UV illumination. Plates were then sprayed with Dragendorff's reagent, prepared by gradually adding $35 \mathrm{ml}$ of water to a solution containing $17 \mathrm{mg}$ of bismuth subnitrate, $200 \mu \mathrm{l}$ of glacial acetic acid, and $800 \mu \mathrm{l}$ of water to which 2.5 $\mathrm{ml}$ of $\mathrm{KI}(400 \mathrm{mg} / \mathrm{ml})$ was added. Average $R_{f} \times 100$ values are CDPCh, 7; PCh, 19; betaine, 35; choline, 50; and ACh, 62 .

Lipid-soluble choline metabolites were separated on silica TLC plates (UV254, Macherey-Nagel) essentially as described by Stein and Smith (1982). Plates were divided into $1 \mathrm{~cm}$ lanes, and 5-20 $\mu \mathrm{l}$ of the chloroformic extract was applied on top of a spot containing marker lipids. Plates were developed in chloroform:methanol:aectic acid:water (75:25: $8: 3$ ), dried, and put into a chamber containing saturated iodine vapors. Average $R_{f} \times 100$ values are lyso-PtdCh, 0 ; sphingomyelin, 11; PtdCh, 21; Ptd-serine, 35; and Ptd-ethanolamine, 61. Plates were put into a fume cupboard for $1-2 \mathrm{hr}$ to remove excess iodine before scintillation counting. To extract the counts from the strips of cellulose and silica, strips were wetted in $0.5 \mathrm{ml}$ of $1 \mathrm{~N} \mathrm{HCl}$, after which $4 \mathrm{ml}$ of scintillant was added. Complete extraction and recovery of the radioactivity applied were obtained after $24 \mathrm{hr}$.

It should be noted that the relative amount of ACh out of the total water-soluble metabolites varied from $10 \%$ to $40 \%$ between culture batches. This was most probably due to a difference in CAT expression, which is regulated by factors in the serum (Iacovitti et al., 1982; Wolinsky and Patterson, 1985). The percentage of PtdCh out of the total radiolabeled choline incorporated also varied between culture batches and also sometimes varied within the same culture set. This appeared to be related to a difference in the rates at which neurites were elongating in each particular culture, as neurite length was limited by the diameter of the coverslip and this was often reached within 3 weeks. Those neurons incorporating larger amounts of choline into $\mathrm{PtdCh}$ consistently had higher amounts of CDP-Ch in the methanol/water extract.

Release of choline metabolites. Release was measured as described previously (Tolkovsky and Suidan, 1987) except that $125 \mu l$ of the control or test solutions was applied onto the coverslip and a $75 \mu \mathrm{l}$ sample was removed and added to ice-cold $5 \mu \mathrm{l}$ glacial acetic acid at cach round. The depolarizing medium containcd (in $\mathrm{mm}$ ) $\mathrm{NaCl}, 90$; $\mathrm{KCl}, 54 ; \mathrm{CaCl}_{2}$ or $\mathrm{BaCl}_{2}, 3$; HEPES, 10 ; with glucose $0.57 \%$; eserine, $15 \mu \mathrm{g} / \mathrm{ml}$; and Tris to bring to $\mathrm{pH} 7.4$.

Histochemistry of cholinesterase activities. Cholinesterase (ChE) activities were detected in single-cell cultures grown on collagen-coated glass coverslips using the staining procedure of Karnovsky and Roots (1964). Staining was carried out at room temperature after washing the cultures $2 \times 5 \mathrm{~min}$ each in $2.5 \mathrm{ml}$ phosphate-buffered saline (PBS). Neurons were fixed for $25 \mathrm{~min}$ in $4 \mathrm{~g} \%$ paraformaldehyde in PBS and washed $3 \times 5 \mathrm{~min}$ each in PBS. Cultures were then incubated for 45 min with $100 \mu$ lof the staining mixture: (in $\mathrm{mm}$ ) acetylthiocholine, 1.6; potassium ferricyanide, 0.5 ; cupric sulfate, 2.7 ; sodium citrate, 4.5 ; and sodium acetate $(\mathrm{pH} 6.5)$, 9. Incubations were performed in the presence or absence of specific ChE inhibitors and in the presence or absence of Triton X-100 (0.3g\%) to identify intra- and extraccllular enzyme activities. Control cultures were incubated without acetylthiocholine. After the incubation, coverslips were blotted, washed $2 \times 5$ min each in PBS, mounted on slides in DePeX (Merck), and photographed with identical exposure times using a Nikon Diaphot microscope.

\section{Results}

Choline uptake and ACh synthesis during acquisition of cholinergic properties and its modulation by depolarization

Figure 1 shows a time course of ${ }^{3} \mathrm{H}$-choline uptake and $\mathrm{ACh}$ synthesis in explants of SCG neurons grown for 2-21 d under cholinergic-inducing conditions. The rate of choline uptake in- 

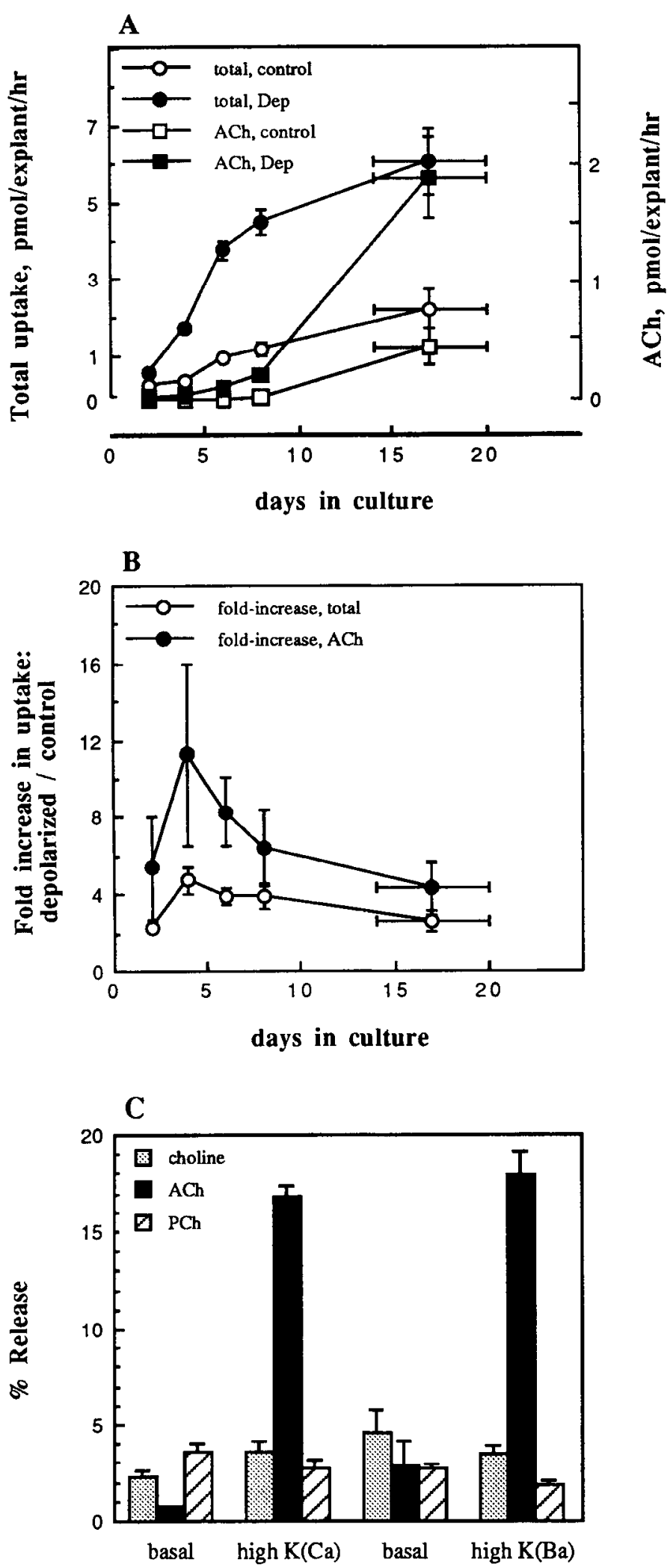

Figure 1. Modulation of choline uptake by depolarization during development of the cholinergic phenotype in SCG neurons. Explants of rat SCG grown between 2 and $21 \mathrm{~d}$ were washed in $\mathrm{L} 15$-saline to remove choline in the growth medium and incubated for $1 \mathrm{hr}$ in L15-saline containing $0.125 \mu \mathrm{M}{ }^{3} \mathrm{H}$-choline, washed, and intracellular metabolites analyzed as described in Materials and Methods. $A$, Total choline uptake and ACh content are shown without or after a $5 \mathrm{~min}$ depolarizing prepulse in high $\mathrm{K}(\mathrm{Ba})$ medium, delivered before the labeling period. creased steadily during this time (Fig. $1 A$ ), in parallel with the outgrowth of neurites, which attained a length of $\sim 6 \mathrm{~mm}$ by 21 d (Tolkovsky and Suidan, 1987). In contrast, $\mathrm{ACh}$ synthesis increased in a parabolic manner: at $2 \mathrm{~d}$ there was $3 \mathrm{fmol} / \mathrm{explant}$ of $\mathrm{ACh}$ per $260 \mathrm{fmol} /$ explant total incorporation $(1.1 \%)$; by 8 $\mathrm{d}$ this increased to $31 \mathrm{fmol} / \mathrm{explant} \mathrm{ACh}$ per $1.2 \mathrm{pmol} / \mathrm{explant}$ total incorporation (2.5\%), and by 2-3 weeks ACh constituted $0.4 \mathrm{pmol} / \mathrm{explant}$ per $2.2 \mathrm{pmol} / \mathrm{explant}$ total incorporation $(20 \%)$ (Fig. 1A). At each time point, some of the cultures were also depolarized for $5 \mathrm{~min}$ in a solution containing $54 \mathrm{~mm} \mathrm{KCl}$ and $3 \mathrm{mM} \mathrm{Ba}^{2+}$ [high $\mathrm{K}(\mathrm{Ba})$ ] before the incubation with ${ }^{3} \mathrm{H}$-choline, conditions similar to those known to elevate choline incorporation into whole SCG (Higgins and Neal, 1982a,b) or PC12 cells (Melaga and Howard, 1981). The depolarizing prepulse markedly enhanced the rate of choline uptake when delivered any time during the culture period. To examine the efficacy of the depolarizing prepulse in augmenting choline transport and $\mathrm{ACh}$ biosynthesis, the values for the radioactivity incorporated after depolarization were normalized to those of the corresponding control values. Figure $1 B$ shows a peak effect of depolarization after $4 \mathrm{~d}$ in culture, the enhancement of incorporation into ACh being substantially larger than that calculated for the enhancement in total uptake. By 3 weeks, however, there was essentially no difference between $\mathrm{ACh}$ and total uptake in the degree of enhancement by depolarization, and this characteristic was also maintained in older cultures.

The increase in choline incorporation in 2-3 week cultures after a depolarizing prepulse in $54 \mathrm{mM} \mathrm{K}^{+}$was dependent on $\mathrm{Ca}^{2+}$, which, at $3 \mathrm{~mm}$, caused a $1.6 \pm 0.2$-fold stimulation of uptake (mean $\pm \mathrm{SEM}, n=2$, quadruplicate determinations) comparcd to $3 \mathrm{mM} \mathrm{Ba}^{+}(2.6 \pm 0.5$-fold increase, mean $\pm \mathrm{SEM}$, $n=6$, triplicate or quadruplicate determinations), and this effect was reduced by $70 \%$ in a $\mathrm{Ca}^{2+}$-free medium containing $0.5 \mathrm{~mm}$ Na-EDTA ( $\mathrm{pH} 7.4$ ). Although these depolarizing conditions were sufficient to evoke the release of ACh (Fig. $1 C$ ) and noradrenaline (Tolkovsky and Suidan, 1987), the enhancement of choline uptake was not dependent on $\mathrm{ACh}$ (or noradrenaline) release, as (1) it was also evident after $2 \mathrm{~d}$ of culture (Fig. $1 A$ ), although at this time labeled $\mathrm{ACh}$ levels were barely detectable, and (2) a 5 min pretreatment with $100 \mu \mathrm{M}$ carbachol (with $3 \mathrm{mM} \mathrm{CaCl}$ ) increased choline uptake to the same levels as $54 \mathrm{~mm} \mathrm{KCl}$ and caused a similar elevation of $\left[\mathrm{Ca}^{2+}\right]_{\text {in }}$, although it failed to induce neurotransmitter release (Suidan et al., 1991). If the enhancement of choline uptake by high $\mathrm{K}^{+}$or carbachol is mediated by an increase in $\left[\mathrm{Ca}^{2+}\right]_{\text {in }}$, this would suggest that enhancement of choline uptake by depolarization does not depend on $\mathrm{ACh}$ releasc, as has becn suggested (Marchbanks, 1975).

\section{Analysis of ${ }^{3} \mathrm{H}$-choline metabolites in cell bodies and neurites}

In 2-3 week cultures incubated for $1 \mathrm{hr}$ with radiolabeled choline, $90 \pm 7 \%$ of the label was found in the water-soluble me-

\footnotetext{
Values are averages of two separate experiments done in triplicate \pm SEM. The values shown at $17.5 \mathrm{~d}$ are averages from six separate experiments performed on explants ranging from 2 to 3 weeks in culture. $B$, Ratios of stimulated to control uptake values were calculated from data shown in $A$. $C$, Three-week explants were preincubated with 0.125 $\mu \mathrm{M}{ }^{3} \mathrm{H}$-choline and subjected to a neurotransmitter-releasing protocol in the presence of $15 \mu \mathrm{g} / \mathrm{ml}$ eserine as described in Materials and Methods. The data are presented as percentage release out of total ${ }^{3} \mathrm{H}$-choline incorporation and show the results of a typical experiment repeated five times.
} 
A

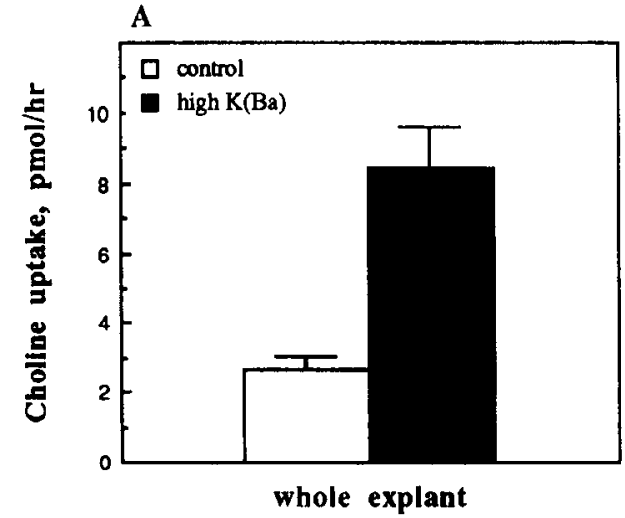

B

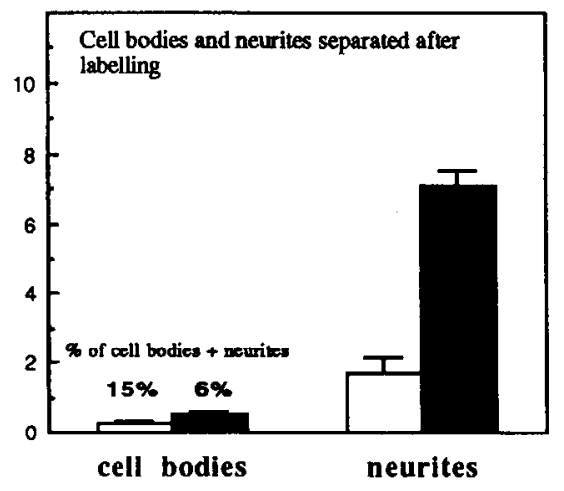

C

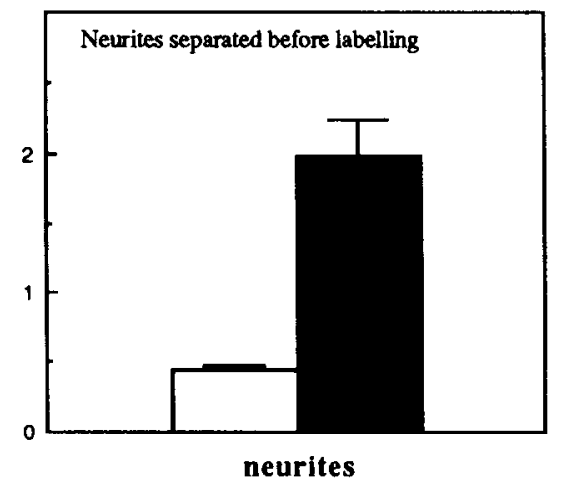

Figure 2. Choline uptake into cell bodies and neurites of cultured SCG neurons. $A$, Explants ( 3 weeks in culture) were incubated with ${ }^{3} \mathrm{H}$-choline without or after a depolarizing prepulse for $5 \mathrm{~min}$ in high $\mathrm{K}(\mathrm{Ba})$ and total choline uptake was analyzed as described in Materials and Methods. $B$, Cell bodies were separated from neurites after the incubation with ${ }^{3} \mathrm{H}$-choline. An analysis of intracellular metabolites is given in Table 1 . $C$, Neurites were separated from the cell bodies before incubation with ${ }^{3} \mathrm{H}$-choline. Each value is the mean \pm SD of triplicate determinations.

tabolites, and $10 \pm 7 \%$ in lipids. The distribution of label between the water-soluble metabolites was choline, $40.7 \pm 8 \%$; $\mathrm{ACh}, 20.5 \pm 4.7 \%$; PCh, $33.9 \pm 9 \%$; and CDP-Ch, $3.1 \pm 0.9 \%$ (mean \pm SEM, $n=6$, triplicate determinations). Less than $1 \%$ was found in betaine, and no labeled glycerophosphocholine was detected. Of the lipid metabolites, $>90 \%$ of label was found in PtdCh, the remaining counts being distributed between sphingomyelin and lyso-PtdCh (or a compound within the migrational zone of lyso-PtdCh).

Since neurons were postmitotic, the increase in choline uptake with age of cultures suggested that the neurites may be the major site of choline incorporation. To investigate the relative contribution of the cell bodies and neurites to the uptake of ${ }^{3} \mathrm{H}$ choline, and whether this would be altered after a depolarizing prepulse, the incorporation of ${ }^{3} \mathrm{H}$-choline was measured in neurites and cell bodies separated after or before the incubation with ${ }^{3} \mathrm{H}$-choline (Fig. 2). In the absence of a depolarizing prepulse, about $85 \%$ of choline uptake occurred in the neurites of 2-3 week cultures (Fig. $2 B$ ). Although ${ }^{3} \mathrm{H}$-choline uptake was enhanced in the entire explant after depolarization (see also Fig. 1), elevation of uptake was more pronounced in the neurites (approximately fourfold) as compared to cell bodies (approximately twofold), thereby reducing the contribution of the cell bodies to total uptake from $15 \%$ to $6 \%$. Figure $2 C$ shows that the increased uptake of ${ }^{3} \mathrm{H}$-choline into neurites after a depolarizing prepulse was not dependent on their connection to the cell bodies, as a similar rise in ${ }^{3} \mathrm{H}$-choline incorporation following high $\mathrm{K}(\mathrm{Ba})$ treatment occurred when neurites were separated from the cell bodies prior to the incubation with ${ }^{3} \mathrm{H}$-choline.

An analysis of the choline metabolites synthesized from ${ }^{3} \mathrm{H}-$ choline in neurites and cell bodies in the absence and presence of a depolarizing prepulse is given in Table 1. In cell bodies, almost all of the ${ }^{3} \mathrm{H}$-choline was incorporated into two metabolites: PCh ( $85 \%$ of the aqueous phase) and PtdCh (92\% of the lipid phase, which formed $\sim 17 \%$ of the total ${ }^{3} \mathrm{H}$-choline incorporated). There was little free choline $(5 \%)$ and only trace amounts of ACh $(3 \%)$. In the neurites, the distribution of label was different: PCh was no longer the major water-soluble metabolite, and nearly equal amounts of label were distributed between ACh (29\%), free choline (32\%), and PCh (34\%). Although there was a slight reduction in the relative distribution of label in neuritic PtdCh (from $\sim 17 \%$ to $\sim 12 \%$ ), the actual amount synthesized by the neurites was still four- to fivefold higher than the amount produced by the cell bodies. After further dissection of the neurite bed into five concentric rings of $\sim 1 \mathrm{~mm}$ cross section before labeling (for method, see Tolkovsky and Suidan, 1987), similar

Table 1. Composition of choline metabolites in cell bodies and in neurites without or after a depolarizing prepulse

\begin{tabular}{|c|c|c|c|c|c|}
\hline & \multicolumn{2}{|c|}{ Intact explants } & \multirow{2}{*}{$\begin{array}{l}\text { Cell bodies } \\
\text { (control }{ }^{a} \text { ) }\end{array}$} & \multicolumn{2}{|l|}{ Neurites } \\
\hline & Control & High $\mathrm{K}(\mathrm{Ba})$ & & Control & High $\mathrm{K}(\mathrm{Ba})$ \\
\hline$\Sigma$ aqueous phase & & & $84 \pm 2$ & $88 \pm 5$ & $91 \pm 3$ \\
\hline Choline & $41 \pm 8$ & $59 \pm 6$ & $5 \pm 2$ & $32 \pm 10$ & $40 \pm 10$ \\
\hline $\mathrm{ACh}$ & $21 \pm 5$ & $20 \pm 5$ & $3 \pm 2$ & $29 \pm 7$ & $32 \pm 7$ \\
\hline $\mathrm{PCh}$ & $34 \pm 9$ & $20 \pm 4$ & $85 \pm 2$ & $34 \pm 10$ & $26 \pm 10$ \\
\hline CDP-Ch & $3 \pm 1$ & $1.2 \pm 0.5$ & $2 \pm 1$ & $4 \pm 2$ & $4 \pm 2$ \\
\hline Lipids & & & $17 \pm 5$ & $12 \pm 5$ & $9 \pm 3$ \\
\hline PtdCh & & & $92 \pm 3$ & $85 \pm 15$ & $92 \pm 4$ \\
\hline
\end{tabular}

Explant cultures were incubated for $1 \mathrm{hr}$ in L15-saline containing $0.125 \mu \mathrm{M}{ }^{3} \mathrm{H}$-choline without or after a depolarizing prepulse of $5 \mathrm{~min}$ with high $\mathrm{K}(\mathrm{Ba})$. Cell bodies were separated from neurites before or after the incubation with ${ }^{3} \mathrm{H}$ choline as shown in Figure 2 and the intracellular choline metabolites were analyzed as described in Materials and Methods. The results for the water-soluble metabolites were calculated as the percentage of total label incorporated into the aqueous phase. Betaine $(\sim 2 \%)$ was detected in cell bodies, but as $<1 \%$ was detected in the neurites it is omitted from the table. The percentage of label in the lipids was calculated from the amount of label in the chloroformic phase. Results were obtained from three to five separate experiments, three explants per experiment (mean $\pm \mathrm{SD}$ ).

${ }^{a}$ The results obtained in cell bodies after high $K(\mathrm{Ba})$ were not significantly different from controls. 
Table 2. The effect of eserine on the incorporation of choline into $\mathrm{ACh}$ and $\mathrm{PCh}$

\begin{tabular}{lcccc} 
[Choline $_{\text {out }}(\mu \mathbf{M})$ & Choline $_{\text {in }}$ & ACh & ACh + choline & PCh \\
\hline 0.15 & $2.9 \pm 0.9$ & $1.4 \pm 0.4$ & $4.3 \pm 1$ & $0.57 \pm 0.17$ \\
$0.15+$ eserine & $1 \pm 0.03$ & $2.6 \pm 0.2$ & $3.6 \pm 0.2$ & $0.77 \pm 0.19$ \\
0.59 & $10 \pm 3.3$ & $2.9 \pm 0.9$ & $12.9 \pm 3.4$ & $2.1 \pm 0.46$ \\
$0.59+$ eserine & $5.9 \pm 1.1$ & $6 \pm 0.7$ & $11.9 \pm 1.3$ & $2.3 \pm 0.63$
\end{tabular}

Explants grown for $14 \mathrm{~d}$ were incubated for $30 \mathrm{~min}$ in L15-saline containing 0.125 or $0.59 \mu \mathrm{M}{ }^{3} \mathrm{H}$-choline $(1.17$ or 4.7 $\mu \mathrm{Ci}$, respectively), washed, and the intracellular metabolites analyzed as described in Materials and Methods. Where indicated, $15 \mu \mathrm{g} / \mathrm{ml}$ eserine was included during the incubation and washes. The values shown represent mean \pm SD of three or four determinations, and are given as pmol/explant except as indicated.

amounts of labeled PtdCh were obtained from each segment (data not shown), suggesting that the incorporation is distributed throughout the neurites.

To examine whether the newly synthesized PtdCh is associated with membranes, we took advantage of the fact that $5 \%$ aqueous acetic acid extracts virtually all of the intracellular water-soluble metabolites (Suidan and Tolkovsky, 1992). Explants were therefore treated with $5 \%$ acetic acid included in three washes applied after the labeling period before the normal extraction procedure. No radioactivity was detected in the watermethanol extract, as expected, but the radioactivity found in the chloroform phase was no different to that of explants washed without acetic acid, suggesting that most of the PtdCh is incorporated within membranes.

Taken together, these results show that neurites have a much higher capacity than cell bodies to incorporate choline into both $\mathrm{ACh}$ and PtdCh, especially after depolarization, and that all of the necessary components for PtdCh biosynthesis from choline are evenly distributed along the neurites.

\section{The kinetics of labeling and the role of reversible reactions in maintaining the steady state}

It was intriguing that the relative distribution of label between the various metabolites was altered by less than $30 \%$ after a depolarizing prepulse although total choline uptake increased by two- to fourfold (Fig. $1 A$, Table 1 ). This suggested that the slowest step in the labeling process is choline transport. In support of this conclusion, no change was observed in the relative distribution of label after a $1 \mathrm{hr}$ incubation in a range of labeled choline concentrations from $0.1-30 \mu \mathrm{M}$, although total uptake increased by about 30 -fold over this concentration range (results not shown). Furthermore, a similar relative distribution of label between the water-soluble metabolites was found as a function of time, with virtually no change between $5 \mathrm{~min}$ and $6 \mathrm{hr}$ of incubation with $0.125 \mu \mathrm{M}{ }^{3} \mathrm{H}$-choline (results not shown), indicating that a steady state is rapidly established between the intracellular choline and its metabolites $\mathrm{ACh}, \mathrm{PCh}$, and $\mathrm{CDP}$ Ch. The amount of PtdCh, however, increased almost linearly as a function of time (up to $10 \mathrm{hr}$ ), with little indication of saturation.

There are two mechanisms for attaining the rapid, steady state distribution of a precursor into its metabolites: (1) by reversible fluxes between the precursor and its product; (2) by a flux through an intermediate(s) into an endpoint product. Since ACh is both synthesized and hydrolyzed in these neurons (Swerts et al., 1984; Goudou et al., 1985), we hypothesized that the rapid attainment of a constant ratio between choline and $\mathrm{ACh}$ is controlled by the activities of CAT and ChE. Otherwise, in the absence of $\mathrm{ChE}, \mathrm{ACh}$ would continue to accumulate with time. We used the general $\mathrm{ChE}$ inhibitor eserine to test the contribution of $\mathrm{ChE}$ activities to the maintenance of a stable $\mathrm{ACh}$ :choline ratio. Table 2 shows that eserine caused the ACh levels to increase by the same amount as choline decreased without any apparent effect on the levels of PCh (or CDP-Ch or PtdCh), thus supporting the suggestion that ACh levels appear to be set by rapid synthesis and degradation.

Eserine is a general inhibitor of both butyryl-ChE (BChE) and $\mathrm{AChE}$, and it has been reported that both $\mathrm{BChE}$ and $\mathrm{AChE}$ are present in sympathetic ganglia (Goudou et al., 1985; Klinar et al., 1985). It is not clear, however, which of these enzymes is responsible for the ChE activity in cultured SCG neurons, and whether they are differentially distributed. Because ACh synthesis was localized mainly in the neurites, we examined the distribution of ChE activities between the cell bodies and the neurites histochemically. Figure 3 shows that total $\mathrm{ChE}$ activity (top row) was due almost entirely to AChE activity (detected using iso-OMPA, a BChE inhibitor; Austin and Berry, 1953) and was located both inside and on the surface of the cell bodies and neurites. However, some $\mathrm{BChE}$ activity in the cell bodies was also detected, as indicated by the activity found in the presence of the AChE inhibitor BW284C51 (Fig. 3, third row). No activity was detected in the presence of both inhibitors (Fig. 3 , bottom row). Thus, it is clear that virtually all of the ChE associated with the neurites is $\mathrm{AChE}$, which may be active both intra- and extracellularly.

In contrast to $\mathrm{ACh}, \mathrm{PCh}$ levels appeared to be determined by a flux of choline through the intermediates PCh and CDP-Ch, into PtdCh. Indeed, PtdCh was the only metabolite whose relative amount increased with time of labeling, suggesting that its rate of breakdown is slow compared to its rate of synthesis. There is some controversy as to whether choline released by hydrolysis of PtdCh activated by depolarization is likely to be an important source of choline for ACh biosynthesis (Millington and Wurtman, 1982; Wecker and Schmidt, 1989; Yavin et al., 1989). To examine whether PtdCh could serve as a reservoir of choline that can be mobilized for ACh synthesis, PtdCh was prelabeled, neurons were then depleted of $\mathrm{ACh}$ by depolarization, and the replenishment of $\mathrm{ACh}$ was examined as a function of the breakdown of prelabeled PtdCh. Table 3 shows that although the level of water-soluble metabolites was reduced by some $30 \%$ when the neurons were depolarized during the wash period, the lipid pool remained stable. To examine the steady state turnover of PtdCh, explants were grown with $28 \mu \mathrm{M}{ }^{14} \mathrm{C}$ choline in the medium for $24 \mathrm{hr}$, washed, and grown further with unlabeled $28 \mu \mathrm{M}$ choline. Table 3 shows that although the amount of labcl in the watcr-soluble metabolites decreased by $55 \%$ during $3 \mathrm{hr}$ of growth in the medium containing unlabeled choline, no such loss of label was detected in the lipids. Furthermore, two depolarizing pulses failed to release ${ }^{14} \mathrm{C}$-choline from the lipids but about $29 \%$ of the labeled water-soluble me- 
- Triton $\mathrm{x}-100$
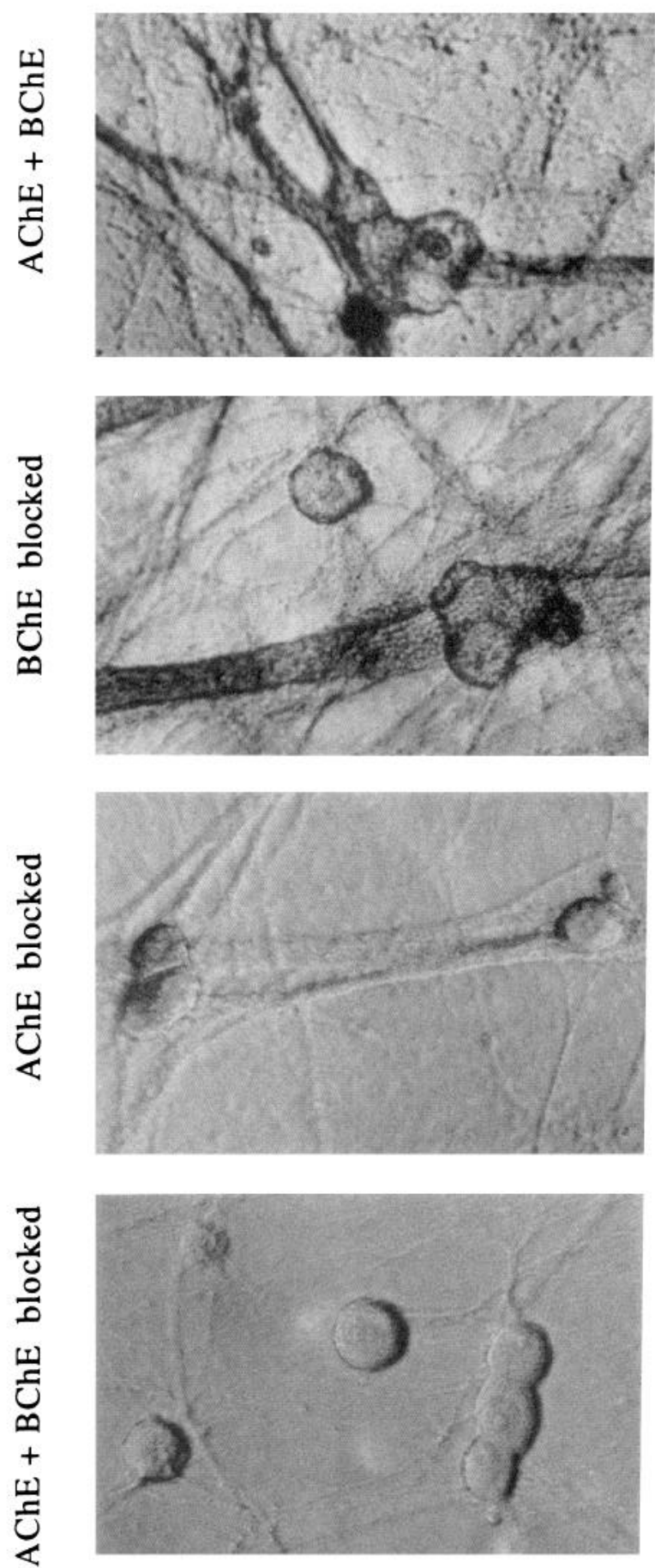

+ Triton $\mathrm{x}-100$
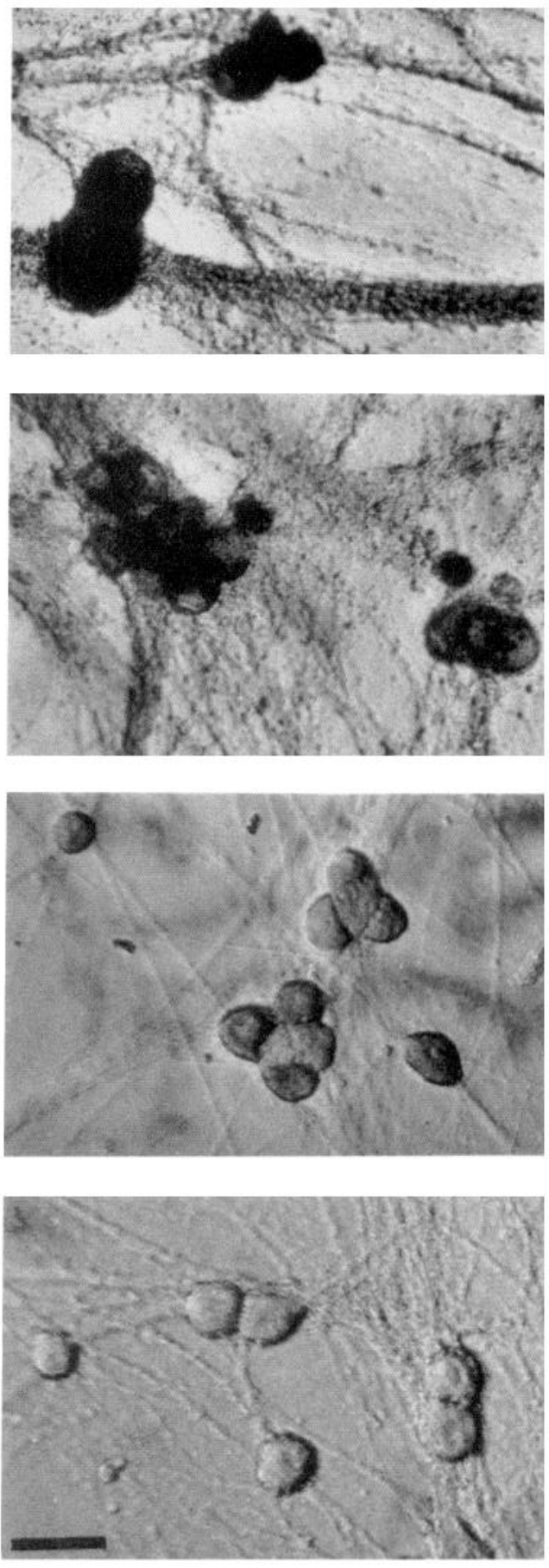

Figure 3. AChE and $\mathrm{BChE}$ activities in SCG neurons. Total ChE, AChE, and $\mathrm{BChE}$ activities were detected histochemically in $25 \mathrm{~d}$ cultures as described in Materials and Methods, using iso-OMPA $(50 \mu \mathrm{M})$ to block BChE and BW284C51 (100 $\mu \mathrm{M})$ to block AChE. The right column shows cultures stained in the presence of $0.3 \%$ Triton X-100. No staining was detected in the absence of acetylthiocholine. Scale bar, $25 \mu \mathrm{m}$.

tabolites were released into the medium during this time (not shown). These observations suggest that the turnover of PtdCh is slow compared to the rate of exchange of intracellular choline with (1) its water-soluble metabolites and (2) with the medium. Thus, in SCG neurons brief depolarizing activities are unlikely to release sufficient choline to be utilized for ACh production, although observation of a decline in labeled PtdCh over $24 \mathrm{hr}$ suggests that a slow release of choline from PtdCh does occur.

\section{Regulation and perturbation of choline metabolism}

Since ACh and PCh levels were found to be very similar under widely varying concentrations and times of incubation with choline, we examined the half-saturation constants $\left(K_{1 / 2}\right)$ and $V_{\max }$ values of CAT and CK for choline. These were calculated from measurement of the amounts of ACh and PCh synthesized over $0.5-1 \mathrm{hr}$ as a function of intracellular choline concentration, altered by varying the concentration of radiolabeled choline in 


\begin{tabular}{|c|c|c|}
\hline Conditions & $\begin{array}{l}\text { Water-soluble metabolites } \\
\text { (pmol/explant) }\end{array}$ & $\begin{array}{l}\text { Lipids } \\
\text { (fmol/explant) }\end{array}$ \\
\hline \multicolumn{3}{|l|}{ 1. Acute effect of depolarization } \\
\hline \multicolumn{3}{|l|}{ No prepulse } \\
\hline Wash $3 \times$ L15 & $1.00 \pm 0.06 \quad(100 \%)$ & $46 \pm 1$ \\
\hline Wash $1 \times \mathrm{L} 15,2 \times$ high $\mathrm{K}(\mathrm{Ba})$ & $0.76 \pm 0.006(76 \%)$ & $50 \pm 1.2$ \\
\hline \multicolumn{3}{|l|}{ Prepulse with high $\mathrm{K}(\mathrm{Ba})$} \\
\hline Wash $3 \times$ L15 & $3.26 \pm 1.03 \quad(100 \%)$ & $161 \pm 26$ \\
\hline Wash $1 \times \mathrm{L} 15,2 \times$ high $\mathrm{K}(\mathrm{Ba})$ & $2.17 \pm 0.04 \quad(66 \%)$ & $150 \pm 42$ \\
\hline \multicolumn{3}{|l|}{ 2. Kinetics of washout } \\
\hline Immediately after incubation & $158 \pm 43$ & $241 \pm 122$ \\
\hline After $1 \mathrm{hr}$ in cold choline & $88 \pm 33$ & $241 \pm 87$ \\
\hline After $2 \mathrm{hr}$ in cold choline & $76 \pm 28$ & $388 \pm 135$ \\
\hline After $3 \mathrm{hr}$ in cold choline & $72 \pm 15$ & $336 \pm 56$ \\
\hline
\end{tabular}

Explants ( 3 weeks in culture) were incubated for $1 \mathrm{hr}$ in the presence of $0.125 \mu \mathrm{M}{ }^{3} \mathrm{H}$-choline $(1.17 \mu \mathrm{Ci})$ and washed three times in L15-saline or once in L15-saline and twice in high $\mathrm{K}(\mathrm{Ba})$. In the kinetic experiment, explants were labeled in the presence of $28 \mu \mathrm{M}{ }^{14} \mathrm{C}$-choline for $24 \mathrm{hr}$, and a washout of label was followed for up to $3 \mathrm{hr}$ in the presence of 28 $\mu \mathrm{M}$ nonradiolabeled choline. It should be noted that after $24 \mathrm{hr}$, no label was detected in the lipids. The results are mean \pm SD of triplicate determinations.

the medium (Fig. 4). The data were fitted to a Michaelis-Menten equation representing a single, saturable substrate binding site, thus assuming that the same pool of choline in $_{\text {in }}$ is simultaneously available to both enzymes. We also assumed that there is a rapid equilibrium (or steady state) established between choline and the two enzymes during $0.5 \mathrm{hr}$ of incubation, a condition that appeared to hold between 0.1 and $30 \mu \mathrm{M}$ [choline] $]_{\text {out }}$. With intracellular choline ranging from 1 to $40 \mathrm{pmol} / \mathrm{explant}$, the $K_{1 / 2}$ values of $44 \pm 16 \mathrm{pmol} / \mathrm{explant}(\mathrm{SE}, 14$ points) and $83 \pm 47$ pmol/explant (SE, 15 points) and the $V_{\max }$ values of $9 \pm 2 \mathrm{pmol} /$ explant $/ \mathrm{hr}$ and $32 \pm 13 \mathrm{pmol} / \mathrm{explant} / \mathrm{hr}$ were derived for $\mathrm{CK}$ and CAT, respectively. Thus, the apparent affinity and $V_{\max }$ values of the two enzymes were remarkably similar, supporting the similarity in the observed choline distribution pattern.

To understand how the allocation of choline is regulated between the ACh- and PtdCh-generating pathways, we attempted to perturb the incorporation of choline either by inhibiting choline transport with $\mathrm{HC}-3$, a competitive inhibitor of the highaffinity choline transporter (Holden et al., 1975; O'Reagan and Collier, 1981; Anderson et al., 1983), or by replacement of $\mathrm{Na}^{+}$ in the medium with $\mathrm{NMG}$, or by inhibiting the storage of $\mathrm{ACh}$ into vesicles with vesamicol (AH5183) (Marien et al., 1987; Kornreich and Parsons, 1988). Figure $5 A$ shows that HC-3 (12.5 $\mu \mathrm{M})$ caused an $88 \%$ inhibition of the uptake of $0.125 \mu \mathrm{M}{ }^{3} \mathrm{H}$ choline, resulting in a similar $85-95 \%$ reduction in the incorporation of choline into each of its metabolites. The effects of replacement of $\mathrm{Na}^{+}$with $\mathrm{NMG}$ are shown in Figure 6. In contrast to HC-3, NMG reduced the amount of choline uptake only partially, by $57 \%, 63 \%$, and $58 \%$, in the presence of the wide range of concentrations of $0.125,15$, and $30 \mu \mathrm{M}$ labeled choline, respectively. Figure $6 \mathrm{~A}$ shows that the amounts of labeled intracellular choline were directly proportional to the concentrations of labeled choline in the medium. Furthermore, when NMG was added with 15 and $30 \mu \mathrm{M}$ extracellular ${ }^{14} \mathrm{C}$-choline, intracellular choline concentrations were reduced to the levels obtained after labeling the cells with $0.125 \mu \mathrm{M}{ }^{3} \mathrm{H}$-choline in the absence of the drug (to $0.49 \pm 0.06$ and $0.57 \pm 0.03 \mathrm{pmol} /$ explant vs $0.56 \pm 0.19 \mathrm{pmol} / \mathrm{explant}$; mean $\pm \mathrm{SD}, n=3$; Table 4). As expected, ACh levels were reduced by $80 \%$, following closcly the reduction in intraccllular choline (Fig. 6B). However, the amounts of PCh (Fig. 6C), CDP-Ch, or PtdCh synthesized (Table 4) remained at the same levels found in the presence of 15 and $30 \mu \mathrm{M}$ choline in the absence of the drug, and were not reduced to match those expected if only $0.125 \mu \mathrm{M}$ choline were present. The effect of NMG was unaltered when ACh consisted of $10 \%$ or $40 \%$ of the intracellular water-soluble choline melabolites. The results obtained with NMG are not due solely to the lack of $\mathrm{Na}^{+}$in the medium, as similar results were obtained when only $70 \mathrm{mM} \mathrm{NaCl}$ was replaced by $\mathrm{NMG}$, or when $1 \mu \mathrm{M}$ vesamicol was added in the presence of normal medium (Fig. $5 B)$.

\section{Discussion}

The experiments described here are concerned with the question of how growing ncurons expressing cholinergic properties control the allocation of choline between the opposing demands of the ACh and PtdCh synthetic pathways. The data show that in SCG neurons with neurites of $\sim 6 \mathrm{~mm}$ length, the bulk of choline is committed into these two pathways in the same cellular compartment, in the neurites, where over $90 \%$ of the $\mathrm{ACh}$ and $\mathrm{PtdCh}$ are synthesized. To support these opposing demands for choline and to maximize the share of choline allotted to each, the $K_{1 / 2}$ and $V_{\max }$ values of CAT and CK, the two enzymes that compete directly for choline, appear to be set at closely matched levels. We also demonstrate that these parameters need not necessarily be matched, however, as drug-induced choline deprivation results in an apparent 10-fold enhancement of CK but not CAT activity, thereby maintaining the potential for normal rates of phospholipid synthesis while relinquishing the production of $\mathrm{ACh}$.

\section{PtdCh synthesis occurs mainly in the neurites}

The rate of choline uptake increased with culture age, together with the increase in neurite outgrowth. Since the neurons are postmitotic, this suggested that the increased choline uptake activity may be located in the neurites, similar to the increased capacity of SCG neurons to synthesize ATP in the growing 
A

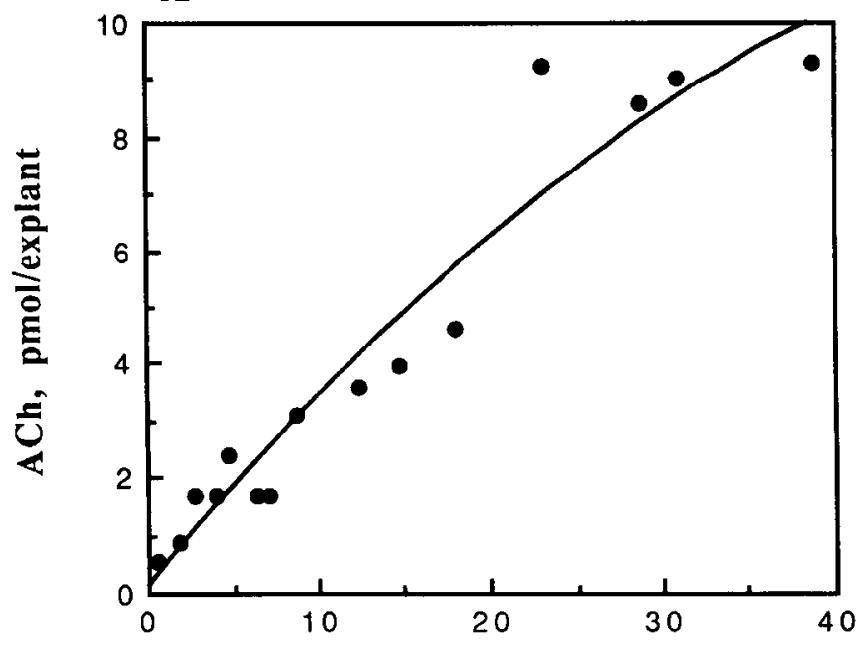

B

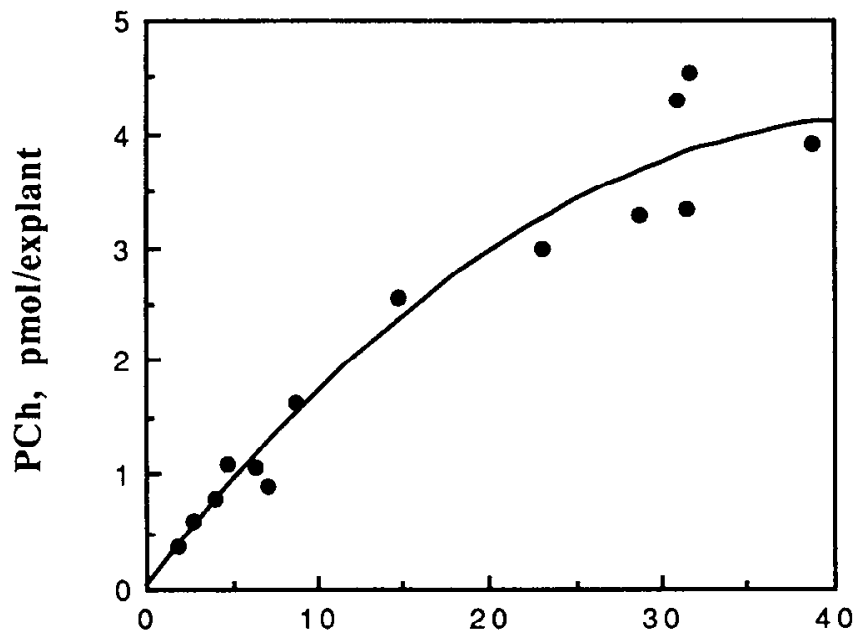

Intracellular labelled choline, pmol/explant

Figure 4. Synthesis of $\mathrm{ACh}$ and $\mathrm{PCh}$ as a function of intracellular choline. Explants (18-23 d in culture) were washed in L15-saline and incubated with $0.125-30 \mu \mathrm{M}{ }^{3} \mathrm{H}$ - or ${ }^{14} \mathrm{C}$-choline in L15-saline for 0.5 $1 \mathrm{hr}$, after which cultures were washed and metabolites were analyzed as described in Materials and Methods. The data were fitted to a Michaelis-Menten kinetic equation using ENZFITTER (Biosoft, Cambridge, UK). The fitted curve is shown. The $V_{\max }$ values derived are $32 \pm 13$ $(\mathrm{ACh})$ and $9 \pm 2(\mathrm{PCh}) \mathrm{pmol} / \mathrm{explant}$. The $K_{\mathrm{t} / 2}$ values are $83 \pm 47$ $(\mathrm{ACh})$ and $44 \pm 16(\mathrm{PCh}) \mathrm{pmol} / \mathrm{explant} / 0.5 \mathrm{hr}$.

neurites (Tolkovsky and Suidan, 1987). The site of choline uptake was therefore determined more precisely by separating neurites from cells bodies before or after labeling, and by examining the uptake in each compartment without or after a depolarizing prepulse (Fig. 2, Table 1). Clearly, most of the choline was incorporated in the neurites, and this activity occurred independently of a functional connection to the cell bodies. Moreover, choline incorporation into PtdCh was distributed throughout the neurites, as each segment in a neurite bed compartmented into five concentric segments with a section of $\sim 1 \mathrm{~mm}$ (Tolkovsky, 1987; Tolkovsky and Suidan, 1987) incorporated choline into PtdCh. Interestingly, a small but consistent increase in
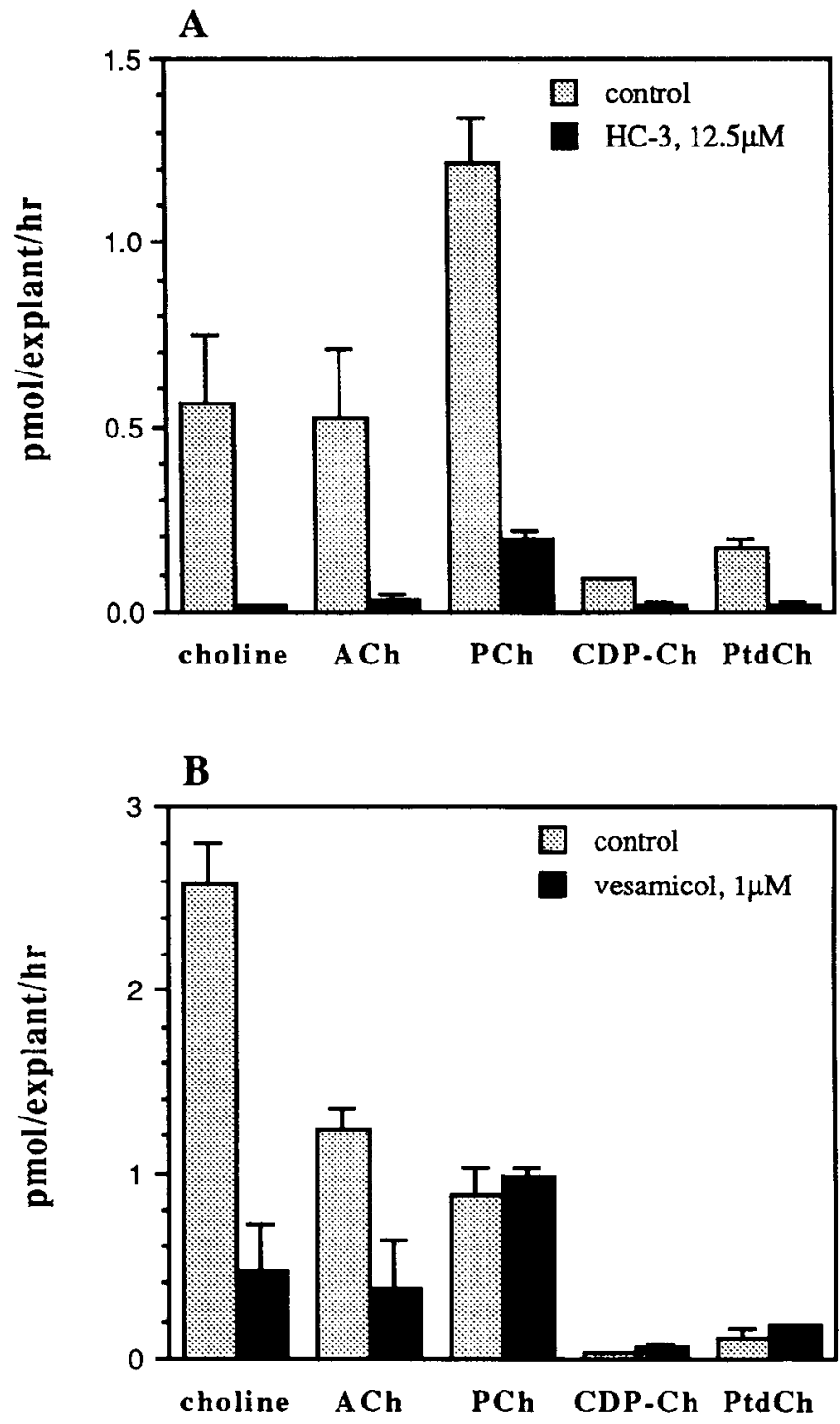

Figure 5. The effects of $\mathrm{HC}-3$ and vesamicol on choline incorporation into SCG neurons. $A$, Explants grown for $23 \mathrm{~d}$ were washed in L15saline containing $12.5 \mu \mathrm{M} \mathrm{HC}-3$, incubated for $1 \mathrm{hr}$ with $0.125 \mu \mathrm{M}{ }^{3} \mathrm{H}-$ choline in the presence of $\mathrm{HC}-3$, washed again, and intracellular metabolites analyzed as described in Materials and Methods. Total ${ }^{3} \mathrm{H}-$ choline uptake was $2.37 \pm 0.53$ or $0.28 \pm 0.02$ pmol/explant (mean \pm SD of triplicate samples) in the absence and presence of $\mathrm{HC}-3$, respectively. $B$, A similar experiment to that described in $A$ was performed on explants grown for $17 \mathrm{~d}$ except that the solutions contained $1 \mu \mathrm{M}$ vesamicol. Total ${ }^{s} \mathrm{H}$-choline uptake was $4.83 \pm 0.31$ or $1.92 \pm 0.52$ pmol/explant (mean \pm SD of triplicate samples) in the absence and presence of vesamicol, respectively.

the amount of choline incorporated was found in the more distal sections, consistent with increased neurite branching in these segments. The increase in the capacity for choline uptake from $2 \mathrm{~d}$ to 3 weeks (9-12-fold) was somewhat higher than that observed for adenylate cyclase activity (6-fold; Tolkovsky, 1987) for adenine uptake into ATP (4-fold) (Tolkovsky and Suidan, 1987) or noradrenaline uptake (7-fold) (Tolkovsky and Suidan, 1987; Tolkovsky et al., 1990), reflecting perhaps the increasing contribution of $\mathrm{ACh}$ to the total choline incorporated.

The newly synthesized lipid appeared to be tightly associated with membranes as it was not extracted after washes with $5 \%$ acetic acid that were sufficient to deplete virtually all of the 

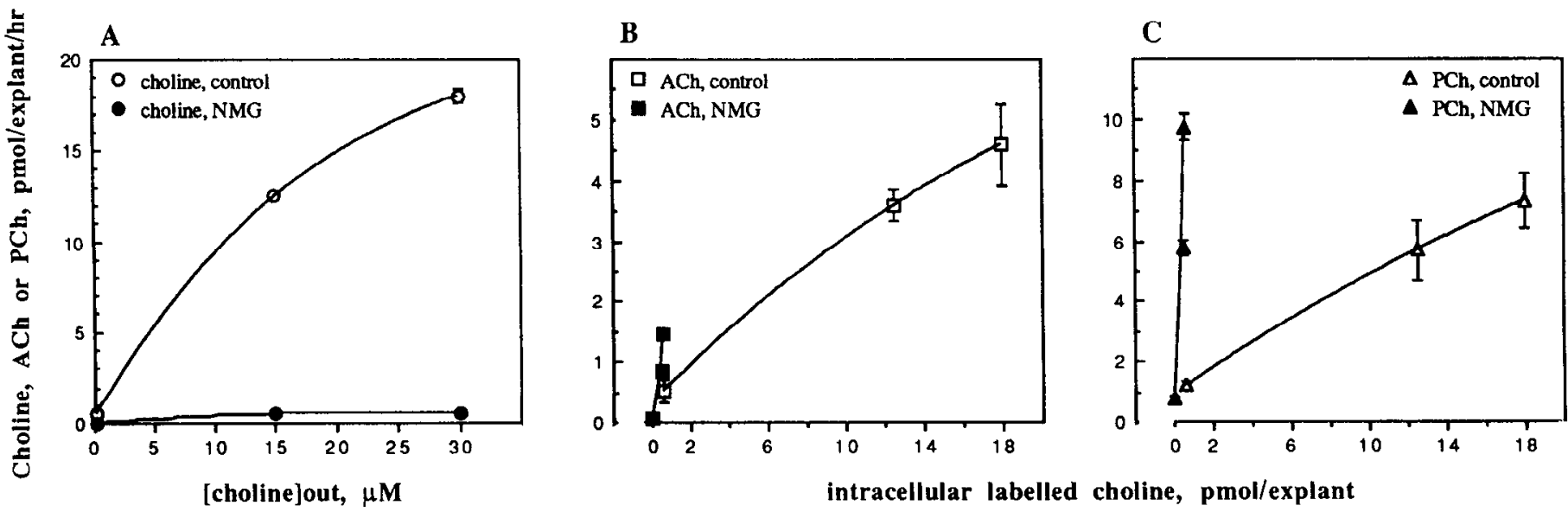

Figure 6. The effect of NMG on the uptake and metabolism of cholinc in SCG ncurons. Explants ( $23 \mathrm{~d}$ in culture) were washed in L15-saline and incubated with $0.125 \mu \mathrm{M}{ }^{3} \mathrm{H}$-choline or with 15 or $30 \mu \mathrm{M}{ }^{14} \mathrm{C}$-choline in L15-saline (containing $140 \mathrm{mM} \mathrm{NaCl}$ ) or in L15-saline in which 140 mM NMG was substituted for $\mathrm{NaCl}$ for $1 \mathrm{hr}$, after which cultures were washed and metabolites were analyzed as described in Materials and Methods. $A$, The amount of intracellular radiolabeled choline is shown as a function of extracellular labeled choline concentration. $B$, The amount of ACh is shown as a function of intracellular labeled choline. $C$, The amount of $\mathrm{PCh}$ is shown as a function of intracellular labeled choline. Results are the mean $\pm S D$, triplicate determinations. Similar results were obtained when 70 mM sodium was substituted with 70 mM NMG (not shown).

water-soluble choline metabolites from the neurites, including small compartments such as intracellular organelles and neurotransmitter storage vesicles. The occurrence of lipid synthesis in neurites is consistent with the findings of Gould and colleagues (Gould et al., 1983; Tanaka et al., 1987), who measured lipid synthesis in extruded axoplasm from myelinated axons, and those of Vance et al. (1991), who looked at SCG neurons grown in compartmentalized culture chambers. In addition to the observations of Vance et al. (1991), we have shown that synthesis of lipid in SCG neurites occurs after complete elimination of their connection to the cell body.

Compared to the rate of increase in total choline uptake, the rate of synthesis of $\mathrm{ACh}$ increased in a parabolic manner with time in culture, the major acceleration in the rate of synthesis occurring between $2-3$ weeks. These kinetics are in keeping with previous observations that the induction of CAT activity (Johnson et al., 1980a,b) in response to factors in the serum (Iacovitti et al., 1982; Wolinsky and Patterson, 1985) accelerates between 2 and 3 weeks, and suggest that neurite outgrowth is not limited by this phenotypic development. We also observed that a brief depolarizing prepulse enhanced the uptake of $0.125 \mu \mathrm{M}$ choline by at least twofold at all culture ages, probably due to the activation of a high-affinity choline uptake system (Mulder et al., 1974; Simon and Kuhar, 1975; Murrin and Kuhar, 1976) with a half-saturation constant of 2-6 $\mu \mathrm{M}$ in SCG neurons (Suidan, 1989). Our observation that the degree of enhancement of choline uptake after depolarization was not directly related to the amount of ACh being synthesized or released (Fig. 1) supports the now prevalent view (see Ducis, 1988, for review) that the activation of the high-affinity choline transporter by a brief depolarization is not directly coupled to ACh synthesis or release (Marchbanks, 1975).

\section{Maintaining PtdCh synthesis in the neurites may be important for growth}

In neurites of 3 week cultures, choline was incorporated into $\mathrm{ACh}$ and $\mathrm{PCh}$ in about equal amounts (Table 1). The nearly equivalent distribution of label among choline, $\mathrm{ACh}$, and $\mathrm{PCh}$, and the time, concentration, and depolarization independence of this pattern of distribution (Table 1) exemplify a unique pattern of labeling when compared to patterns of labeling found in fibroblasts or in cholinergic nerve endings. We suggest that this pattern stems from the specific requirements of growing neurons expressing cholinergic properties, although it is also possible that these results reflect the particular stage of cholinergic development attained. Thus, in proliferating cultures of 3T3 fibroblasts, we observed that intracellular choline constituted only $\sim 1 \%$ of total label incorporated, while PCh, CDP-

\section{Table 4. Choline incorporation in the presence or absence of NMG}

\begin{tabular}{llccccc}
$\begin{array}{l}{[\text { Choline }} \\
(\mu \mathrm{M})\end{array}$ & [Choline $_{\text {in }}$ & ACh & PCh & CDP-Ch & PtdCh \\
\hline 0.125 & $0.56 \pm 0.19$ & $0.52 \pm 0.19$ & $1.2 \pm 0.13$ & $0.09 \pm 0.01$ & $0.17 \pm 0.02$ \\
$0.125+\mathrm{NMG}$ & $0.01 \pm 0.001$ & $0.02 \pm 0.007$ & $0.78 \pm 0.08$ & $0.05 \pm 0.01$ & $0.15 \pm 0.05$ & $1.01 \pm 0.1$ \\
15 & $12.5 \pm 0.17$ & $3.6 \pm 0.26$ & $5.7 \pm 1$ & $0.72 \pm 0.1$ & $0.62 \pm 0.02$ & $23.1 \pm 1.6$ \\
$15+\mathrm{NMG}$ & $0.49 \pm 0.06$ & $0.84 \pm 0.04$ & $5.8 \pm 0.26$ & $0.84 \pm 0.2$ & $0.96 \pm 0.07$ & $8.93 \pm 0.1$ \\
30 & $18 \pm 0.4$ & $4.6 \pm 0.67$ & $7.35 \pm 0.9$ & $0.78 \pm 0.03$ & $0.72 \pm 0.00$ & $31.5 \pm 2$ \\
$30+\mathrm{NMG}$ & $0.57 \pm 0.03$ & $1.47 \pm 0.07$ & $9.76 \pm 0.4$ & $1.00 \pm 0.16$ & $0.79 \pm 0.02$ & $13.6 \pm 0.7$
\end{tabular}

Explants ( $23 \mathrm{~d}$ in culture) were incubated for $1 \mathrm{hr}$ in the indicated concentrations of radiolabeled choline in L15-saline containing $140 \mathrm{~mm} \mathrm{NaCl}$ or $140 \mathrm{~mm} \mathrm{NMG}$. Care was taken to ensure that the NMG-containing solution was well buffered at $\mathrm{pH} 7.4$. The results are the means \pm SD of triplicate determinations, and are given as $\mathrm{pmol} /$ explant/hr except as indicated. Some of these results are plotted in Figure 4. Total incorporation is shown as Total. 
Ch, and PtdCh accounted for, respectively, 50-72\%, 10-30\%, and $12-20 \%$ of the remaining label after $1 \mathrm{hr}$ of labeling with $0.125 \mu \mathrm{M}{ }^{3} \mathrm{H}$-choline (H. S. Suidan, unpublished observation). No ACh was detected. In contrast, in cholinergic synaptosomes derived from mouse striatum (Yamamura and Snyder, 1973) choline and ACh accounted for $27 \%$ and $70 \%$ of the total label incorporated after $1 \mathrm{hr}$ incubation with $0.5 \mu \mathrm{M}{ }^{3} \mathrm{H}$-choline, with PCh contributing only $3 \%$ to the label. Fven after the synaptosomes were exposed to high $(100 \mu \mathrm{M})$ external choline, where the relative distribution of label changed to $63 \%$ choline and $16 \% \mathrm{ACh}, \mathrm{PCh}$ still accounted for only $10 \%$ of the intracellular label. Thus, when choline is used primarily for lipid synthesis, as in fibroblasts, the cell can afford to direct all of the available choline into the lipid pathway, by expressing a high-affinity CK. When choline is used primarily for ACh synthesis, as in synaptosomes, an excess of choline accumulates as free choline, presumably because the activity and/or the concentration of $\mathrm{CK}$ is low in this particular compartment. In growing neurons expressing cholinergic properties, where both $\mathrm{ACh}$ and $\mathrm{PCh}$ (and lipid) are synthesized in the same cellular compartment, it appears that the best strategy to maximize choline allocation into both pathways is to keep the levels of all three components, namely, choline, ACh, and $\mathrm{PCh}$, at about equal levels. This is achieved either by maintaining rapid, reversible fluxes between the components, as between choline and ACh (by use of CAT and $\mathrm{AChE}$ ), or by rapid fluxes through to an irreversible pathway, as with choline to PCh to PtdCh. In addition, a steady state is achieved such that the distribution of choline is neither time nor concentration dependent.

This strategy would be further supported by adjusting the halfsaturation constants of the two key enzymes, CAT and CK, to near-equal affinities for choline; indeed, we have calculated from data similar to that in Figures 4 and 5 , generated over a wide range of [choline] $]_{\text {out }}$, that the apparent $K_{1 / 2}$ and $V_{\max }$ values for $\mathrm{CK}$ and CAT are very similar. Taken together, these results illustrate how well the choline metabolism in these neurons is designed to maximize the feeding of a common precursor, choline, into two competing but equally important pathways.

The proposal that the coexistence of ACh and PtdCh is functionally important is further supported when the labeling pattern in the neurites and cell bodies is compared. Thus, cell bodies, which synthesize the vesicular components destined to travel into neurites by a fast axonal transport system, express a similar metabolism to fibroblasts (Table 1) while the neurites exhibit a mixed fibroblast/synaptosomal phenotype. The possibility that $\mathrm{PtdCh}$ is also synthesized directly from choline by base exchange activity is unlikely, as there was a direct correlation between the levels of CDP-Ch and PtdCh under all experimental conditions.

What is the role of lipid synthesis in the neurites? One possibility is that this lipid synthesis is used to support neurite elongation. We noted that the amount of choline allocated into the lipid pathway was highly dependent on the presence of active neurite elongation. Thus, neurites that had reached the end of the coverslip and were unable to continue to grow round the edges had a decreased incorporation of choline into PtdCh compared to neurites that were elongating in a near linear rate. It was therefore interesting to calculate by how much the lipid synthesis in the neurites could contribute to neurite elongation. If a single molecule of hydrated PtdCh takes up $0.64 \times 10^{-12}$ $\mathrm{mm}^{2}$ (Janiack et al., 1979) and the surface area of a neurite membrane added after $24 \mathrm{hr}$ in culture is $1.57 \times 10^{-3} \mathrm{~mm}^{2}$ (based on a radius of $0.5 \mu \mathrm{m}$ and an elongation of $0.5 \mathrm{~mm} / 24$ hr), one can calculate that about $5 \times 10^{9}$ molecules of PtdCh will be required to cover the entire surface of both leaflets of the newly synthesized membrane. The maximal rate of synthesis of PtdCh per neuron per $24 \mathrm{hr}$ under growth conditions (with about $50 \mu \mathrm{M}$ extracellular choline) is calculated to bc about 100 fmol, which is equivalent to about $6 \times 10^{10}$ molecules. Thus, it appears that neurites of 3 week cultures would have the capacity to provide sufficient PtdCh to sustain their own elongation.

Perhaps lipid synthesis in the neurites supports the transport of membrane particles into the plasma membrane (Ellisman and Lindsey, 1983). It is not clear why, despite the relatively straightforward assays that could demonstrate the presence of functional ER in axons (Kennedy, 1962; Bishop and Bell, 1988) and the presence in axons of ER-like tubular structures, often referred to as axoplasmic reticulum (see, e.g., Matthews, 1973), most attention has been focused on the possible role of these membranes in mediating fast axonal transport rather than membrane biogenesis (see, e.g., Grafstein and Forman, 1980; Rambourg and Droz, 1980). It has also been suggested that retrograde transport of lipids from injured axons to cell bodies is important for regeneration (Bisby, 1984). However, the significance of these observations will have to be reassessed in light of the findings that the majority of lipid synthesis and some lipid methylation (Pfenninger and Johnson, 1981) occur locally in the neurites.

\section{Drug-induced limits on choline provision favor the $C K$-catalyzed pathway}

Having demonstrated that CK and CAT activities compete equally for the labeled choline, we examined what would happen if provision of choline were perturbed. We have shown that increased supply of choline after a depolarizing prepulse had no substantial effect on choline distribution into its metabolites. We therefore turned to limiting the supply of choline using various inhibitors of choline transport or $\mathrm{ACh}$ storage. When HC-3 was used to block choline transport, both ACh and PCh levels (and those of CDP-Ch and PtdCh) were reduced in direct proportion to the reduction in intracellular choline, with extracellular choline varying between 0.125 and $30 \mu \mathrm{M}$. When, however, sodium in the medium was replaced by NMG, intracellular choline and $\mathrm{ACh}$ synthesis were both reduced in equal proportions (Fig. 4) but PCh, CDP-Ch, and lipid synthesis levels were unaffected, as if no NMG was present.

To account for the data, we have constructed the following minimal model for the transitions between the various key choline metabolites:

$$
\text { [choline }]_{\text {out }} \stackrel{k_{1}}{\underset{k_{2}}{\leftrightarrows}} \|_{[\mathrm{ACh}]} k_{4}[\text { acetyl-CoA] }
$$

This model assumes that a rapid equilibrium is established between choline and $\mathrm{ACh}$ or $\mathrm{PCh}$ such that $k_{3}$ and $k_{4}$ represent the net forward flux of choline into its respective metabolites (namely, $k_{3}$ and $k_{4}=k_{f} / k_{f}+k_{b}$, where $k_{f}$ and $k_{b}$ are the forward and reverse rate constants; CoA, coenzyme A).

In the case of HC-3, a decrease in $k_{1}$ and/or an increase in $k_{2}$ would be sufficient to explain the results, although the possibility that $\mathrm{HC}-3$ directly inhibits choline binding to CAT and CK 
Table 5. Kinetic parameters for model of Iransitions between choline, $\mathrm{ACh}$, and $\mathrm{PCh}$

\begin{tabular}{|c|c|c|c|c|c|c|c|}
\hline & \multicolumn{2}{|c|}{ Parameters $\left(\mathrm{hr}^{-1}\right)$} & & \multicolumn{4}{|c|}{$\begin{array}{l}\text { Fractional concentration } \\
\text { of choline metabolites }\end{array}$} \\
\hline & \multirow[b]{2}{*}{ Control } & \multirow[b]{2}{*}{$+\mathrm{NMG}$} & & \multicolumn{2}{|l|}{ Control } & \multicolumn{2}{|l|}{$+\mathrm{NMG}$} \\
\hline & & & & $\begin{array}{l}\text { Ob- } \\
\text { served }\end{array}$ & $\begin{array}{l}\text { Pre- } \\
\text { dicted }\end{array}$ & $\begin{array}{l}\text { Ob- } \\
\text { served }\end{array}$ & $\begin{array}{l}\text { Pre- } \\
\text { dicted }\end{array}$ \\
\hline$k_{1}$ & 1 & 1 & {$[\text { Choline }]_{\text {out }}$} & 0.80 & 0.78 & 0.92 & 0.91 \\
\hline$k_{2}$ & 12 & 200 & {$[\text { Choline }]_{\text {in }}$} & 0.045 & 0.052 & 0.0013 & 0.0036 \\
\hline$k_{3}[\mathrm{ATP}]$ & 2 & 20 & [PCh] & 0.117 & 0.103 & 0.078 & 0.075 \\
\hline$k_{4}[\mathrm{AcCoA}]$ & 1 & 1 & [ACh] & 0.043 & 0.051 & 0.004 & 0.0037 \\
\hline
\end{tabular}

The model is presented in the Discussion. The numbers were derived from a simulation of the following equations that define the ratios of intracellular choline ([choline $\left.]_{\mathrm{in}}(t)\right), \mathrm{ACh}([\mathrm{ACh}](t))$, and $\mathrm{PCh}([\mathrm{PCh}](t))$ at any time to that of extracellular choline at time zero, $[\text { choline }]_{\text {out }}\left(t_{0}\right):[\text { choline }]_{\text {in }}(t) /[\text { choline }]_{\text {out }}\left(t_{0}\right)=k_{1} /\left(\lambda_{2}-\lambda_{1}\right)\left\{\exp \left(-\lambda_{1} t\right)-\exp \left(-\lambda_{2} t\right)\right\} ;$ $[\mathrm{ACh}] t /[\text { choline }]_{\text {out }}\left(t_{0}\right)=k_{1} k_{4}\left\{1 / \lambda_{1} \lambda_{2}-\exp \left(-\lambda_{1} t\right) / \lambda_{1}\left(\lambda_{2}-\lambda_{1}\right)-\exp \left(-\lambda_{2} t\right) / \lambda_{2}\left(\lambda_{2}-\lambda_{1}\right)\right\} ;[\mathrm{PCh}] t /[\operatorname{choline}]_{\text {out }}\left(t_{0}\right)=k_{1} k_{3}\{1 /$ $\left.\lambda_{1} \lambda_{2}-\exp \left(-\lambda_{1} t\right) / \lambda_{1}\left(\lambda_{2}-\lambda_{1}\right)-\exp \left(-\lambda_{2} t\right) / \lambda_{2}\left(\lambda_{2}-\lambda_{1}\right)\right\} ;$ where $\lambda_{1} \lambda_{2}=k_{1}\left(k_{3}+k_{4}\right), \lambda_{1}+\lambda_{2}=k_{1}+k_{2}+k_{3}+k_{4}=$ sum, and $\left(\lambda_{2}-\lambda_{1}\right)=\sqrt{\left\{\text { sum }^{2}-4 k_{1}\left(k_{3}+k_{4}\right)\right\}}$, with $k_{3}=k_{f} / k_{f}+k_{b}$ for PCh, $k_{4}=k_{f} / k_{f}+k_{b}$ for ACh, and $k_{1}$ set arbitrarily at 1 $\mathrm{hi}^{-1}$. AcCoA, acetyl coenzyme A.

cannot be excluded (Ducis, 1988). The case of NMG is more complex. In Table 5, the predicted relative concentrations of the four metabolites are compared with the observed values for control and NMG-treated cells. It can be seen that the theoretical and observed values for all four metabolites coincide very closely. Examination of the apparent rate constants shows that in addition to the increase by NMG of $k_{2}$ from a relative rate constant of 12 to $200 \mathrm{hr}^{-1}$ (thereby causing a decrease in apparent affinity of the choline transporters for $30 \mu \mathrm{M}$ choline, presumably due to the replacement of sodium by NMG) the model predicts a 10 -fold increase in $k_{3}[\mathrm{ATP}]$, the parameter that governs the rate of PCh synthesis. It is clear that the effect of NMG is not due to the removal of sodium because similar results were obtained when only $50 \%$ of the sodium was replaced by NMG. Furthermore, vesamicol added in the presence of normal sodium concentrations had similar effects. One possible explanation is that deprivation of choline or reduction of sodium, or NMG and vesamicol, may directly or indirectly modify the kinetic parameters of $\mathrm{CK}$, thereby increasing its activity/ affinity for the remaining choline. This effect would be amplified if either AChE activity were concomitantly increased or CAT activity were to decrease. An opposing change in CK and CAT would be compatible with the observations of Ando et al. (1987), who showed that the activities of a crude extracts of $\mathrm{CK}$ and CAT from SCG ganglia are increased or decreased in opposite directions after prior incubation of sympathetic ganglia with various concentrations of choline, potassium, and sodium. In addition, Uchida and Yamashita (1990) have shown that the specific activity of a purified CK from rat brain is augmented by some polyamines and positively charged ions, by a decrease in the $K_{m}$ for ATP and a rise in $V_{\max }$. If NMG can enter the cells, an activation of $\mathrm{CK}$ would be expected. However, it is also possible that the low sodium (with $\mathrm{NMG)}$ ) or vesamicol divert labeled choline into a pool containing very low unlabeled choline that is only accessible to CK and not to CAT. This would result in an apparent increase in the rate of PCh, CDP$\mathrm{Ch}$, and PtdCh production. The possibility that the enzymes of the PtdCh-synthesizing pathway may form a functional compartment linked to the high-affinity choline transporter has been suggested by George et al. (1989), who showed that electropermabilized glioma cells are able to synthesize PtdCh from choline but not from PCh or CDP-Ch. The exact mechanism of this activation is currently under investigation.
Given the substantial amounts of choline committed to the PtdCh-synthesis pathway in the presence of submicromolar concentrations of choline, and the preferred allocation into the PtdCh-synthetic pathway when choline provision is perturbed, we conclude that growing sympathetic neurons with mixed adrenergic/cholinergic properties, in contrast to CNS neurons (Wurtman, 1992), have more robust mechanisms for preserving PtdCh synthesis as compared to ACh synthesis. Now that the basic pattern of choline allocation has been established, we are examining whether similar regulation occurs after a stronger induction of cholinergic properties imposed by, for example, choline differentiating factor (LIF) (Fukada, 1985) or ciliary neurotrophic factor (Saadat et al., 1989).

\section{References}

Anderson DC, King SC, Parsons SM (1983) Pharmacological characterization of acetylcholine transporter system in purified Torpedo electric organ synaptic vesicles. Mol Pharmacol 24:48-54.

Ando M, Iwata M, Takahama K, Nagata Y (1987) Effects of extracellular choline concentrations and $\mathrm{K}^{+}$depolarization on choline $\mathrm{ki}-$ nase and choline acetyltransferase activities in sympathetic ganglia excised from rats. J Neurochem 48:1448-1453.

Austin L, Berry WK (1953) Two selective inhibitors of cholinesterase. Biochem J 54:695-700.

Bisby MA (1984) Retrograde axonal transport and neuronal regeneration. Adv Neurochem 6:45-63.

Bishop WR, Bell RM (1988) Assembly of phospholipids into cellular membranes: biosynthesis, transmembrane movement and intracellular translocation. Annu Rev Cell Biol 4:579-610.

Boksa P, Mykita S, Collier B (1988) Arachidonic acid inhibits choline uptake and depletes acetylcholine content in rat cerebral cortical synaptosomes. J Neurochem 50:1309-1318.

Chun LLY, Patterson PH (1977) Role of nerve growth factor in development of rat sympathetic neurones in vitro: effect on acetylcholine production. J Cell Biol 75:712-718.

Ducis I (1988) The high affinity choline uptake system. Handb Exp Pharmacol 86:409-437.

Ellisman MH, Lindsey JD (1983) The axoplasmic reticulum within myelinated axons is not transported rapidly. J Neurocytol 12:393411.

Fonnum F, Frizell M, Sjostrand J (1973) Transport, turnover and distribution of choline acetyltransferase and acetylcholine esterase in the vagus and hypoglossal nerves of the rabbit. $\mathbf{J}$ Neurochem 21 : $1109-1120$.

Fukada K (1985) Purification and partial characterisation of a cholinergic differentiating factor. Proc Natl Acad Sci USA 82:8795-8799.

George TP, Morash SL, Cook HW, Byers DM, Palmer FBStC, Spence MW (1989) Phosphatidylcholine biosynthesis in cultured glioma 
cells: evidence for channeling of intermediates. Biochim Biophys Acta 1004:283-291.

Goudou D, Verdiere-Sahaque M, Rieger F (1985) External and internal acetylcholinesterase in rat sympathetic neurones in vivo and in vitro. FEBS Lett 186:54-58.

Gould RM, Pant H, Gainer H, Tytell M (1983) Phospholipid synthesis in the squid giant axon: incorporation of lipid precursors. J Neurochem 40:1293-1299.

Grafstein B, Forman DS (1980) Intracellular transport in neurons. Physiol Rev 4:1167-1283.

Hatori H, Kanfer J (1985) Synaptosomal phospholipase D: potential role for providing choline for acetylcholine biosynthesis. J Neurochem 45:1578-1584.

Hawrot E, Patterson PH (1979) Long term culture of dissociated sympathetic neurons. Methods Enzymol 58:574-578.

Higgins AJ, Neal MJ (1982a) Potassium activation of $\left[{ }^{3} \mathrm{H}\right]$ choline accumulation by isolated sympathetic ganglia of the rat. $\mathrm{Br} \mathrm{J}$ Pharmacol 77:573-580.

Higgins AJ, Neal MJ (1982b) Effect of potassium depolarization and preganglionic stimulation on the metabolism of $\left[{ }^{3} \mathrm{H}\right]$ choline in rat isolated sympathetic ganglia. Br J Pharmacol 77:581-590.

Holden JT, Rossier J, Beaujouan JC, Guyenet P, Glowinski J (1975) Inhibition of high affinity choline transport in rat striatal synapotosomes by alkyl bisquaternary ammonium compounds. Mol Pharmacol 11:19-27.

Iacovitti L, Park DH, Joh TH, Bunge RP (1981) Dual expression of transmitter synthesis in cultured autonomic neurones. J Neurosci 1:685-690.

Janiack MJ, Small DM, Shipley GG (1979) Temperature and compositional dependence of the structure of hydrated dimyristoyl lecithin. J Biol Chem 254:6068-6078.

Johnson MI, Ross CD, Meyers M, Spitznagel EL, Bunge RP (1980a) Morphological and biochemical studies on the development of cholinergic properties in cultured sympathetic neurones: correlative changes in choline acetyltransferase and synaptic vesicle cytochemistry. J Cell Biol 84:680-691.

Johnson MI, Ross CD, Bunge RP (1980b) Morphological and biochemical studies on the development of cholinergic properties in cultured sympathetic neurones: dependence on age. J Cell Biol 84:692704.

Karnovsky MJ, Roots LJ (1964) A 'direct coloring' thiocholine method for cholinesterases. J Histochem Cytochem 12:219-221.

Kennedy EP (1962) The metabolism and function of complex lipids. Harvey Lect 57:143-171.

Klinar B, Kamaric L, Sketelj J, Brzin M (1985) Properties of acetylcholinesterase and non-specific cholinesterase in rat superior cervical ganglion and plasma. Neurochem Res 10:797-808.

Kornreich WD, Parsons SM (1988) Sidedness and chemical kinetic properties of the vesamicol receptor of cholinergic synaptic vesicles. Biochemistry 27:5262-5267.

Liscovitch M, Slack B, Blusztajn JK, Wurtman RJ (1987) Differential regulation of phosphatidylcholine biosynthesis by 12- $O$-tetradecanoylphorbol-13-acetate and diacylglycerol in NG108-15 neuroblastoma $\times$ glioma hybrid cells. J Biol Chem 262:17487-17491.

Longo FM, Hammerschlagg R (1980) Relation of somal lipid synthesis to the fast axonal transport of protein and lipid. Brain Res 193:471485 .

Marchbanks RM (1975) Biochemistry of cholinergic neurons. Handb Exp Psychopharmacol 6:99-228.

Marchbanks RM, Israel M (1971) Aspects of acetylcholine metabolism in the electric organ of Torpedo marmorata. J Neurochem $18 ; 439$ 448.

Marien MR, Parsons SM, Altar CA (1987) Quantitative autoradiography of brain binding sites for vesicular acetylcholine transport blocker 2-(4-phenylpiperidino)cyclohexal (AH5183). Proc Natl Acad Sci USA 84:876-880.

Matthews MR (1973) A light and electron microscope study of the cellular response to axonal injury in the superior cervical ganglion of the rat. Philos Trans R Soc Lond 264;479-508.

Melaga NP, Howard BD (1981) Choline and acetylcholine metabolism in PC12 secretory cells. Biochemistry 20:4477-4483.

Millington WR, Wurtman RJ (1982) Choline administration elevates phosphorylcholine concentrations. J Neurochem 38:1748-1752.

Mobley WC, Shenker A, Shooter EM (1976) Characterization and isolation of proteolytically modified nerve growth factor. Biochemistry 15:5543-5551.

Mulder AH, Yamamura HI, Kuhar MJ, Snyder SH (1974) Release of acetylcholine from hippocampal slices by potassium depolarization: dependence on high affinity choline uptake. Brain Res 70:372-376.

Murrin LL, Kuhar MJ (1976) Activation of high affinity choline uptake by depolarizing agents. Mol Pharmacol 12:1082-1090.

O'Reagan SR, Collier B (1981) Factors affecting choline transport by the rat SCG during and following stimulation and the relationship between choline uptake and acetylcholine synthesis. Neuroscience 6:511-520

Pelech SL, Vance DE (1984) Regulaticn of phosphatidylcholine biosynthesis. Biochim Biophys Acta 779:217-251.

Pfenninger KH, Johnson MP (1981) Nerve growth factor stimulates phospholipid methylation in growing neurites. Proc Natl Acad Sci USA 78:7797-7800.

Rambourg A, Droz B (1980) Smooth endoplasmic reticulum and axonal transport. J Neurochem 35:16-25.

Ross D, Johnson M, Bunge R (1977) Development of cholinergic characteristics in adrenergic neurones is age dependent. Nature 267: 536-539.

Rubin E (1985) Development of the rat superior cervical ganglion: ingrowth of preganglionic axons. J Neurosci 5:685-696.

Saadat S, Sendtner M, Rohrer H (1989) Ciliary neurotrophic factor induces cholinergic differentiation of rat sympathetic neurones in culture. J Cell Biol 108:1807-1816.

Simon JR, Kuhar MJ (1975) Impulse-flow regulation of high affinity choline uptake in cholinergic nerve terminals. Nature 255:162-163.

Stein J, Smith GA (1982) Techniques in lipids and membrane biochemistry. In: Techniques in life sciences, Vol B4/I, pp B401/1-10. New York: Elsevier Biomedical.

Suidan HS (1989) Regulation of cyclic AMP metabolism in cultured sympathetic neurones. PhD thesis, Cambridge University.

Suidan HS, Tolkovsky AM (1992) Simultaneous analysis of cyclic AMP accumulation and ATP metabolism in cultured cells preincubated with $\left[2-{ }^{3} \mathrm{H}\right]$ adenine. Anal Biochem 205:159-165.

Suidan HS, Murrell RD, Tolkovsky AM (1991) Carbachol and bradykinin elevate cyclic AMP and rapidly deplete ATP in cultured rat sympathetic neurones. Cell Regul 2:13-25.

Swerts J-P, Le Van Thai A, Vigny A, Weber MJ (1984) Regulation of enzymes responsible for neurotransmitter synthesis and degradation in cultured rat sympathetic neurones. Dev Biol 100:1-11.

Tanaka T, Yamaguchi H, Kishimoto Y, Gould RM (1987) Lipid metabolism in various regions of the squid giant nerve fiber. Biochim Biophys Acta 922:85-94.

Tolkovsky AM (1987) Newly synthesized catalytic and regulatory subunits of adenylate cyclase are expressed in neurites of cultured sympathetic neurones. J Neurosci 7:110-119.

Tolkovsky AM, Suidan HS (1987) Adenosine 5'-triphosphate synthesis and metabolism in neurites of cultured sympathetic neurones. Neuroscience 23:1133-1142.

Tolkovsky AM, Walker AE, Murrell RD, Suidan HS (1990) $\mathrm{Ca}^{2+}$ transients are not required as signals for long-term neurite outgrowth from cultured sympathetic neurons. J Cell Biol 110:1295-1306.

Uchida T, Yamashita S (1990) Purification and properties of choline kinase from rat brain. Biochim Biophys Acta 1043:281-288.

Vance JE, Pan D, Vance DE, Campenot RB (1991) Biosynthesis of membrane lipids in rat axons. J Cell Biol 115:1061-1068.

Wecker L, Schmidt DE (1989) Central cholinergic function: relationship to choline administration. Life Sci 25:375-384.

Wolinsky EJ, Patterson PH (1985) Rat serum contains a developmentally regulated cholinergic inducing activity. J Neurosci 5:15091512.

Wurtman RJ (1992) Choline metabolism as a basis for the selective vulnerability of cholinergic neurones. Trends Neurosci 15:117-122.

Yamamura HI, Snyder SH (1973) High affinity transport of choline into synaptosomes of rat brain. J Neurochem 21:1355-1374.

Yavin E (1976) Regulation of phospholipid metabolism in different cells from rat brain cerebral hemispheres in culture. J Biol Chem 251: 1392-1397.

Yavin E, Tanaka Y, Ando S (1989) Phospholipid derived choline intermediates and acetylcholine synthesis in mouse brain synaptosomes. J Neurosci Res 24:241-246. 